\title{
Illumination-Independent Reflectance Information Acquirement for Leaf Water Potential Measurement on the Example of Satsuma Mandarin
}

\author{
Kriston-Vizi, J. ${ }^{1}$, Umeda, M. ${ }^{2}$, Miyamoto, K. ${ }^{3}$ and Ferenczy, A. ${ }^{4}$ \\ ${ }^{1}$ Szent Istvan University, Faculty of Horticulture Science, Technical Department, \\ H-1118 Budapest,Villányi út 29_43.,Hungary, kriston@omega.kee.hu \\ ${ }^{2}$ Division of Environmental Science and Technology, Graduate School of Agriculture, \\ KyotoUniversity, Sakyo-ku Kyoto,606-8502,Japan,umeda@elam.kais.kyoto-u.ac.jp \\ ${ }^{3}$ Wakayama Research Center of Agriculture, Forestry and Fisheries, \\ 751-1 Oki, Kibi-cho,Arida-gun Wakayama,643-0022,Japan,kmiyamo@cypress.ne.jp \\ ${ }^{4}$ Szent Istvan University, Faculty of Horticulture Science, Department of Mathematics and Informatics, \\ H-1118 Budapest, Villányi út 29-43.,Hungary,toni@omega.kee.hu
}

\begin{abstract}
Summary: Mandarin fruit sugar content can be increased when subjecting the satsuma mandarin tree (Citrus unshiu MARC. var. satsuma) to moderate water stress by mulching during the period of active sugar accumulation, thereby fruit quality improvement can be realized. In the frame of the precision agriculture production system, a non-destructive measuring method development became necessary based on remote sensing, field spectroscopy and image analysis, to be able to measure the degree of water stress. Large amount of visual information have been recorded at ground level, in near infrared, red and green channels by a false color digital camcorder designed specially for remote sensing applications. A method have been found to be able to calculate the absolute reflection of mandarin leaf surface by comparing leaf reflectance with known reference target reflectance, thereby established the basis of further studies in this topic. Leaf absolute reflection can be measured reliably, under variable natural illumination at field conditions. Functional correlation can be searched between visual information and leaf water potential measured by PMS pressure chamber.
\end{abstract}

Key words: image analysis, precision agriculture, remote sensing, mandarins, satsumas, field spectroscopy

\section{Introduction}

\section{Background}

Japan developed a strong citrus industry, based primarily on satsuma mandarin because it is tolerant to citrus canker and freeze-hardy. Citrus production in Japan reached its peak in the late $70 \mathrm{~s}$ and since then is decreasing every year partially because dietary habits have changed. The recent decreases in consumption trends of satsumas in Japan have resulted in a decrease in production. Japanese citrus growers have to compete by producing more attractive and higher quality fruit. One quality-improving factor is sugar content. Increased sugar content of mandarin fruit makes it more attractive for the customer and enables the grower compete with candy, soft drinks and ice cream producers whose products are marketed in a sophisticated way with a great deal of advertising (Iwagaki, 1997).

Yakushiji et al. (1998) reported increased sugar accumulation in peel, locular membrane, and juice sac of satsuma mandarin when plants were exposed to moderate water stress.
Mulching is one of the various production techniques, being used to increase sugar content of mandarin fruit by subjecting the roots to water stress during the period of active sugar accumulation, which begins in July. For mulching plastic covers like thore made by DuPont Tyvek are suitable because they contain sub-micron holes through which water vapor can pass but rainwater can not. After the mulch has been applied, the soil gradually dries out.

The term 'field spectroscopy' was introduced by Longshaw (1974) and its usage is supported by several researchers. "Field spectroscopy involves the study of the interrelationships between the spectral characteristics of objects and their biophysical attributes in field environment" (Milton 1987). In this case the spectral characteristics means the reflectance at some spectral channels, and objects mean individual leaves or full canopy of either one tree or a whole orchard. A simpler method of measuring the above mentioned objects' reflectance is to compare the radiance of those objects to that of the radiance of a portable reflectance target having known characteristics. Palmer (1982) lists the desired characteristics of such a reference target, and 
suggests the Kodak Gray Card (previously also called as Kodak Neutral Card) to be the standard reflectance target. Milton (1989) evaluated spectral reflectances of Kodak Gray Card over the range $400-1100 \mathrm{~nm}$. Results show that consistency between cards selected from a single batch is gêod.

\section{Objective}

To extract large amount of numeric information froma visual information source for measuring mandarin leaf water potential non-destructively. Objective also contains developing a method to obtain a target (e.g. mandarin leaf) reflectance result independent from the momentary illumination conditions at near infrared, red and green channels.

\section{Material and method}

\section{Experiment Arrangements and Plant Materials}

This study was carried out in Japan at the Wakayama Research Center of Agriculture, Forestry and Fisheries, Fruit Tree Experiment Station, located in Wakayama Prefecture, 70 kilometers southwest from Osaka.

Mandarin trees (Citrus unshiu MARC. var. satsuma) on Miyagawa Wase strain were used as experimental plants. The orchard contained 28 year old trees, row spacing and planttoplant distance was $4 \mathrm{~m} \times 2 \mathrm{~m}$, respectively. The trees' height was around $2.5 \mathrm{~m}$. Four sample trees were selected at different elevations, 3 of them were grown under normal conditions, 1 was mulched since July 20, 2002. 4 leaves per tree were analyzed, from different canopy levels, from L1 the lowest and L4 the highest, respectively. For mulching DuPont Tyvek cover was used which allows soil moisture evaporation, but drains rain water.

Experiment date: November 21-22, 2002. The experiment was repeated four times as an outdoor measurement series: November 21. 1500 h, November 22. $0700 \mathrm{~h}, 1000 \mathrm{~h}, 1400 \mathrm{~h}$.

\section{Experimental Instrumentation}

\section{Silvacam Digital Video Camcorder}

For digital recording a false color 3 channel CCD digital video camcorder 'Silvacam' was used made by VTT, built into a JVC GY-DV500 camcorder body (hereafter: camcorder). (Silvacam specifications) This camcorder was tailored to both of airborne and ground-based remote sensing applications, especially for observing vegetation. Spectral intensities are recorded at the following spectral channels, encoded into the standard RGB color channels (Table 1).

Additional camcorder specifications (JVC GY-DV500 specifications):

- Lens: Fujinon S14 × 7.3B12, Power Zoom.

- Image pickup devices:1/2-inch interline CCD $\times 3$.
Table 1 Silvacam Camcorder Spectral Channel Perceptional Specifications

\begin{tabular}{|l|c|c|}
\hline $\begin{array}{c}\text { Color Channel Name } \\
\text { on Digital Output }\end{array}$ & $\begin{array}{c}\text { Spectral Channel } \\
\text { Wavelength Range (nm) }\end{array}$ & Spectral Channel Name \\
\hline Red ( R ) & $760-900$ & NIR \\
\hline Green ( G ) & $580-680$ & Red \\
\hline Blue (B) & $490-580$ & Green \\
\hline
\end{tabular}

- Color separation optical system: F1.4 3-color separation prism.

- Number of effective pixels: 380,000 pixels $((\mathrm{H}) 768 \times$ (V) 494).

- Color system : NTSC (R-Y, B-Y encoder).

- Output video format: Mini DV.

\section{Reflectance Targets}

Two types of objects were used as reflectance targets. One is the Kodak Gray Card (hereafter: GC as Gray Card) with known characteristics, the other is a calibration paper with 4 different grayscale level panels (hereafter: CP as Calibration Paper) (Figure 1.)

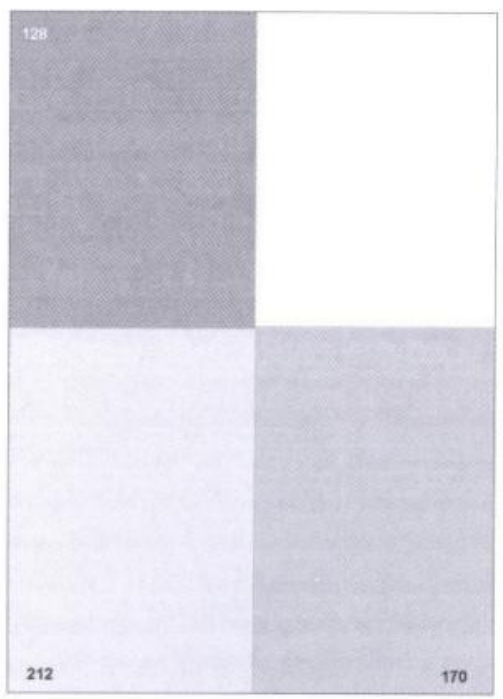

Figure 1 Calibration Paper with 4 different grayscale level panels.

The specifications of the CP:

- Paper material: Recycled Paper G70 A4 size, made by Toppan Forms Co. Ltd., Japan.

- Printer: Hewlett-Packard LaserJet 5000 Series PCL 6 was used to print the gray rectangle panels: 212,170 , 128. The panel 255 was the pure paper surface.

PC specifications:

- CPU: Intel Pentium III $672 \mathrm{MHz}$

- RAM: $400 \mathrm{MB}$

- $\mathrm{HD}: 40 \mathrm{~GB}$ 


\section{Softwares}

Ulead VideoStudio 6 SE Basic was used for video capturing from Mini DV tape via IEEE 1394 Firewire interface to uncompressed AVI file format on PC. Individual frames were extracted using IrfanView version 3.80. Aphelion version 3.2 was used to analyze individual frames using a macro developed by the author to be able to extract numeric data from many frames automatically. SPSS version 10.0 was used for statistical analysis.

\section{Recording methods}

\section{Digital Video Recording Method}

Digital Video was recorded in the orchard after white balance calibration by the camcorder. Object distance from the camcorder was $\sim 0.5 \sim 1.5 \mathrm{~m}$, shooting hand-held, using the zoom feature when necessary, that the leaf can cover the maximum possible image surface. Image layout was arranged the way to show the leaf to measure, and at least one of the CP plates. (Figure 2) To avoid underexpose or overexpose at certain channels when using autoiris feature, video was recorded using manual iris too. Macro focusing ring was used for closeup shooting. Images were shot on whole trees and whole orchard too.

As a wide-angle lens was used, some vignetting effect occurred on images, when shooting at wideopen aperture. In that case some parts of the images at the corners became darker and could not be used for measuring.

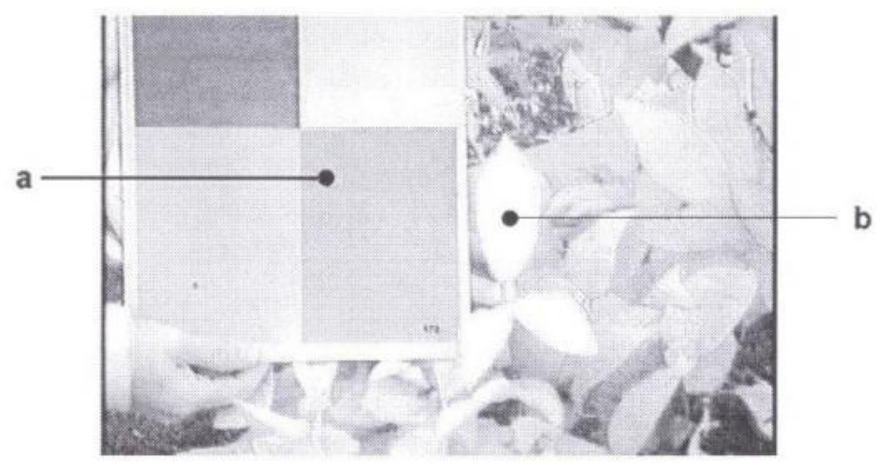

Figure 2 An image layout: CP is shown on the left side (a), and mandarin leaf to be measured is indicated by (b).

\section{Image Analysis Scheme}

1. DV tape was played by Silvacam camcorder and DV data stream was transferred electronically via the firewire to the computer's hard disk. File specifications:

> uncompressed Microsoft AVI file,

- Field order A,

- NTSC drop frame (29.97 fps),

- $720 \times 480$ pixel resolution,

- DV Video Encóder Type 1.

2. Type 1 AVI file was converted into Type 2 AVI file.
3. Frames were extracted from Type 2 AVI file into bitmap (BMP) file. File specifications:

- compression: none,

> color depth: 24 bits per pixel (RGB)

4. The RGB bitmap file is splitted into 3 grayscale channels representing NIR, Red, Green spectral channels as described in Table 1.

5. All greyscale images were segmented and numerical information was extracted as a frequency table.

\section{Absolute Reflectance Calculation}

This experiment is based on measuring reflectance of mandarin leaves under field conditions. The light source is the sun and any weather change influencing illumination conditions (e.g. some clouds cover the sky) lead to effect the reflectance of mandarin leaves. To obtain a reflectance result independent from the momentary illumination conditions, a portable reflectance target having known characteristics was used as a reference.

After image analysis, the result is two or more frequency tables. One represents the leaf object, the other(s) represent the $\mathrm{CP}$ plate(s) as a reference. A histogram can be plotted using frequency tables, which shows a Gauss distribution. Weighted average was calculated as e.q. (1).

$$
\bar{x}_{a, b}=\frac{\sum_{i=1}^{k} f_{i} x_{i}}{\sum_{i=1}^{k} f_{i}} \quad k=254
$$

Where $\bar{x}_{a}$ and $\bar{x}_{b}$ weighted averages of a mandarin leaf and a surrounded $\mathrm{CP}$ plate respectively in grayscale intensity values [0-255]. embed $f_{1}$ is the frequency and $\bar{x}$ represents the grayscale quantization level.

$$
r=\frac{\bar{x}_{a}}{\bar{x}_{b}} \quad\left[\%_{R E L}\right]
$$

Where $r$ is the mandarin leaf's relative reflectance in proportion to a CP plate which is identified to be $100 \%$.

$$
R_{\text {leaf }}=R_{\text {(Tpplate }} * r \quad\left[\%_{\text {ABS }}\right]
$$

$R_{\text {leaf }}$ is the mandarin leaf's absolute reflectance in proportion to a $\mathrm{CP}$ plate absolute reflectance $\left(R_{\text {CPplate }}\right)$, as described at e.q. (4). When calculating absolute reflectance of CP plates, the equations (1) and (2) were used, where $\bar{x}_{a}$ and $\bar{x}_{b}$ represented weighted averages of a CP plate and GC respectively.

$$
R_{\text {Crplate }}=R_{G(C:} * r \quad[\% \text { ABS }]
$$

Whe $R_{G C}^{N I R}=23.16 \%_{A B S} ; R_{G C}^{R}=18.91 \%_{A H S} ; R_{G C}^{G i}=19.40 \%_{A B S}$ based on (Milton 1989). 
Absolute reflectance calculations are presented at Table 2 where

$$
\bar{R}=\frac{\sum_{i=1}^{n} R_{\text {CPplate }}}{n}
$$

The sample sizes of Table 2 are indicated at e.q. (6) and (7).

$$
\begin{gathered}
n=\sum F=899 \\
N=899 * \sum_{k=1}^{k} p=339154284 \quad k=3
\end{gathered}
$$

Where $\mathrm{n}$ means the number of analyzed frames, $\mathrm{N}$ means the number of analyzed pixels, $k$ represents the number of channels.

\section{Results and discussion}

\section{Applying CP}

The reason why CP is necessary is standing the demand that Palmer (1982) raised on reference targets, such as its known reflectance should preferably be near the mean reflectance of the sample. Numerous $(N \approx 8000000$ see Table 3.) measurements show that

$$
R_{\text {leaf }}^{N I R} \approx 50 \%_{A B S} ; \quad R_{\text {leaf }}^{R} \approx 6 \%_{A B S} ; R_{\text {leaf }}^{G} \approx 8 \%_{A B S} .
$$

In the case of an improper camcorder iris setting, the image can be underexposed i.e. on NIR channel the intensity of most pixels scatter between 1-254, but on R and G channels the intensity of most pixels become 0 . Pixels with 0 greyscale intensity value can not be evaluated, because 0 can mean that the intensity of the given pixel is either $\mathbf{0}$ or less than zero but the camcorder indicates every pixel's intensity value as 0 that is under of the perception range of the CCD panel from below. This equivocality is the reason why 0 intensity values must be omitted. Similarly, pixels with intensity value 255 are overexposed, their real intensity values either $\mathbf{2 5 5}$ or over the perception range of CCD panel, and camcorder indicates those as 255. (Figure 3)

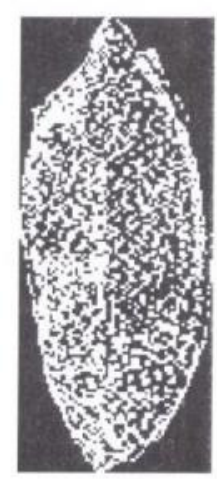

Figure 3 An example for leaf overexposure. On this leaf image white and gray pixels indicate $230-254$ intensity values, while black pixels indicate those ones whose intensity is 255 .
Because of this equivocality pixels with 255 greyscale intensity value are also omitted and only pixels with $1 \leq x \leq 254$ intensity values were taken into account.

The CP's pure paper surface (panel 255) is a surface whose absolute reflectance is near the mean absolute reflectance of $R_{\text {leaf }}^{\text {NIR }}$ (Table 2). In the case of an image with overexposed reference target surface at NIR channel, one of the darker panels can be used as a reference target surface. All panels' absolute reflectances must be determined at all channels as accurately as possible, thus being indifferent which panel to use for calculating the leaf's absolute reflectance.

\section{Absolute Reflectance of CP plates}

Under clear sky, bright sunny field conditions Digital Video was shot on GC and CP. Image layout contained only $\mathrm{GC}$ and $\mathrm{CP}$, under the same illumination conditions. (Figure 4)

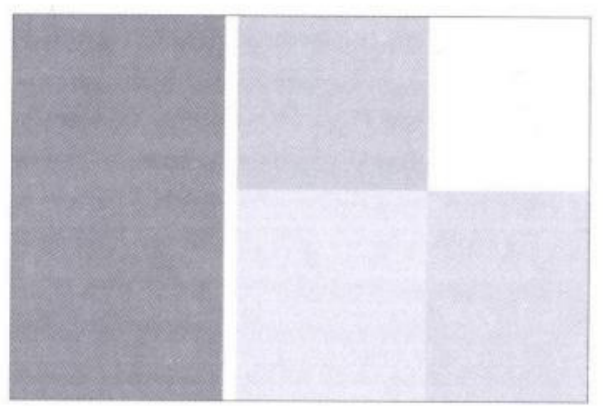

Figure 4 Image layout for determining CP plates' absolute reflection. $\mathrm{GC}$ is at left side, $\mathrm{CP}$ with 4 plates is at right side of the figure

Absolute reflectance of $\mathrm{CP}$ was calculated by equations (4)-(7). Results are shown at Table 2.

Table 2 Calibration Paper plates absolute reflectances.

\begin{tabular}{|l|c|c|c|}
\hline & $\begin{array}{c}\text { Absolute } \\
\text { Reflectance } \\
\text { at NIR Channel } \\
\bar{R}^{N I R}[\%]\end{array}$ & $\begin{array}{c}\text { Absolute } \\
\text { Reflectance } \\
\text { at R Channel } \\
\bar{R}^{R}[\%]\end{array}$ & $\begin{array}{c}\text { Absolute } \\
\text { Reflectance } \\
\text { at G Channel } \\
\bar{R}^{G}[\%]\end{array}$ \\
\hline CPplate 255 [paper color] & 48.51 & 53.00 & 49.83 \\
\hline CPplate 212 & 45.29 & 43.50 & 43.29 \\
\hline CPplate 170 & 36.38 & 39.32 & 38.08 \\
\hline CPplate 128 & 33.53 & 33.33 & 32.19 \\
\hline
\end{tabular}

\section{Difference Between Mandarin Leaf Absolute Reflectances Calculated By Different CP Plates}

Since different CP plates can be used to calculate mandarin leaf absolute reflectance, it is important to make certain of consistence the mandarin leaf absolute reflectance when it is calculated by all different CP plates (Table 3). The mandarin leaf absolute reflectance result should be independent of the factor, that which CP plate was used as a reference. 
Table 3 A mandarin leaf absolute reflectances calculated by all different CP plates

$\mathrm{n}=40 ; \mathrm{N}=8672160$

\begin{tabular}{|c|c|c|c|c|c|c|}
\hline & NIR255 & NIR212 & NIR 170 & NIR 128 & R255 & $\mathrm{R} 212$ \\
\hline$R_{\text {leaf }}$ Mean $\left[\%_{\mathrm{ABS}}\right]$ & 49.95 & 50.62 & 42.25 & 51.05 & 6.53 & 5.91 \\
\hline \multirow[t]{2}{*}{$R_{\text {leaf }}$ Std. Deviation } & 0.408 & 0.596 & 0.5 & 0.779 & 0.435 & 0.41 \\
\hline & $\mathrm{R} 170$ & $\mathrm{R} 128$ & G255 & $\mathrm{G} 212$ & G170 & G128 \\
\hline$R_{\text {leaf }}$ Mean $\left[\%_{\mathrm{ABS}}\right]$ & 6.01 & 6.01 & 8.31 & 7.78 & 7.66 & 7.83 \\
\hline$R_{\text {leaf }}$ Std. Deviation & 0.426 & 0.438 & 0.706 & 0.669 & 0.673 & 0.691 \\
\hline
\end{tabular}

Figure 5 shows $R_{\text {leaf }}$ mean values of Table 3 describing a mandarin leaf absolute reflectances calculated by different $\mathrm{CP}$ plates. Linear regression lines were fitted. $R_{\text {leaf }}$ mean value calculated by plate 170 at NIR channel was offset therefore omitted.

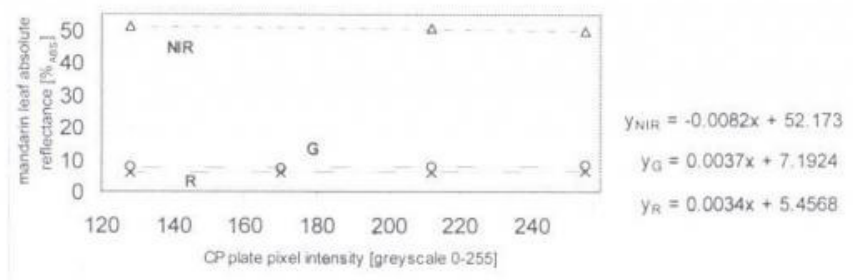

Figure $5 \mathrm{~A}$ mandarin leaf absolute reflectances calculated by all different CP plates

$$
\bar{R}_{\text {leaf }}^{N I R}=50.54 \%_{A B S}: \quad \bar{R}_{\text {leaf }}^{G}=7.89 \%_{A B S} ; \quad \bar{R}_{\text {leaf }}^{R}=6.11 \%_{\text {ABS }} .
$$

\section{Conclusions}

To be able to correlate leaf images taken at different times and illumination conditions and analyze the property changes between two intervals, a method was developed to get the absolute leaf reflectance value at given spectral channels for remote sensing applications.

Almost zero slope of linear regression lines fitted on calculated leaf absolute reflectances indicate, that any of the $4 \mathrm{CP}$ plates can be used to calculate the leaf absolute reflectance except the plate 170 at NIR channel.

As a further research, ground-level image data collection method can be improved by installing the camcorder onto an image analysis-based steering control tractor (Láng et al. 1998, 2000, 2001), making image recording automated at higher level.

Data collecting and image analysis methods described in this paper can provide a basis for researching the functional correlation between mandarin leaf water potential measured by PMS pressure chamber and visual information.

\section{References}

Iwagaki, I. (1997): Citrus Production In Japan: New Trends In Technology. Food and Fertilizer Technology Center. Available at: http://www.agnet.org/library/article/eb440.html. Accessed on 5 Aug. 2002.

JVC GY-DV500 specifications. Available at: http://www.uncstv. org/training/JVC.pdf. Accessed on 22 Apr. 2003.

Láng, Z. (1998): Automatic Steering Control of Plantation Tractor Based on Image Processing. Hungarian Agricultural Engineering, 11: $66-68$.

Láng, Z. (2000): Precision farming alkalmazhatóságának kutatása a gyümölcstermesztésben. MTA AMB Kutatási és Fejlesztési Tanácskozás, Gödöllổ.

Láng, Z. \& Molnár, S. (2000): Image Processing Based Steering Control of a Plantation Tractor. Proceedings AgEng Conference: 51-52, Warwick.

Láng, Z. \& Molnár, S. (2000): Számítógépes képfeldolgozáson alapuló automatikus traktorirányítás modellkísérleteinek elsố eredményei. MTA AMB Kutatási és Fejlesztési Tanácskozás, Gödöllố. Láng, Z., Umeda, M., Misao, Y., Molnár, S. \& Morimoto, E. (2001): Results of the Joint Research of Image Processing Based Tractor Steering. International Conference on $\mathrm{R}+\mathrm{D}$ in Agricultural Engineering, Gödöllổ.

Longshaw, T.G. (1974): Field spectroscopy for multispectral remote sensing: an analytical approach. Applied Optics, 13: 1487-1493.

Milton, E.J. (1987): Principles of field spectroscopy. Int. J. Remote Sensing, 10 (6): 1041-1047.

Milton, E.J. (1989): On The Suitability of Kodak Neutral Test Cards as Reflectance Standards. Int. J. Remote Sensing, 10 (6): 1041-1047.

Palmer, J.M. (1982): Field Standards of Reflectance. Photogrammetric Engineering and Remote Sensing. 48 (10): 1623-1625.

Palmer, J.M. (1982): Field standards of reflectance. Photogrammetric Engineering and Remote Sensing, 48: 1623-1625.

Silvacam specifications. Available at: http://www.vtt.fi/tte/ research/tte1/tte14/prod/silvacam.html. Accessed on 22 Apr. 2003. Yakushiji, H., Morinaga, K. \& Nonami, H. (1998): Sugar Accumulation and Partitioning in Satsuma Mandarin Tree Tissues and Fruit in Response to Drought Stress. J. Amer. Soc. Hort. Sci. 123 (4): 719-726. 